when surgery would be hazardous. Even when a main renal arterial thrombus is present some blood may flow around it, as shown in Case 7 (see also Bellman and Odén, 1960), and the work of Morris et al. (1955) has underlined the protective value of perfusion at even subfiltration arterial pressures for the survival of renal tissue.

TABle II.-Pyelographic, Arteriographic, and Renographic Findings in

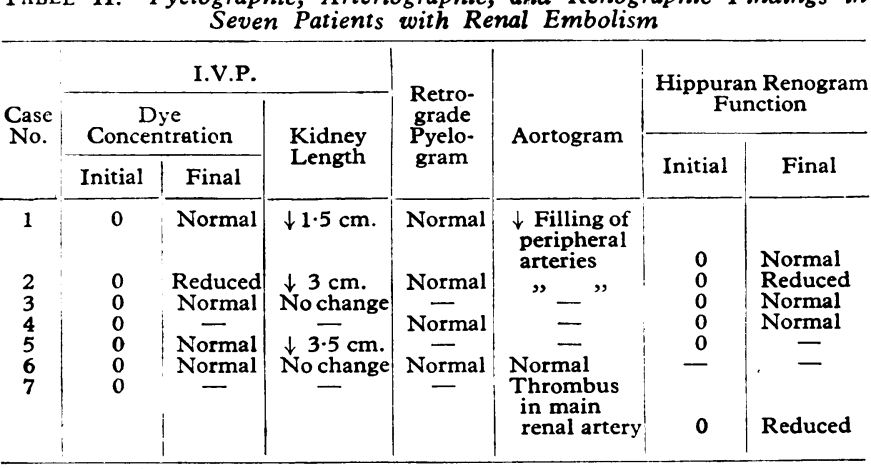

The incidence of hypertension following renal embolism is unknown, but in the cases we describe the arterial pressure did not rise during the period of observation. This varied from 2 to 19 months after embolism, exceeding six months in four patients.

Finally, it should be noted that despite persistent atrial fibrillation none of these patients were receiving anticoagulant therapy. The occurrence of such an episode is a clear indication for anticoagulants, but more general use of anticoagulant treatment for persistent atrial fibrillation might have prevented the renal and extrarenal emboli which occurred in these patients.

We wish to thank Dr. D. N. Croft for carrying out hippuran renography, Mr. C. J. Anders for referring Case 2, and Dr. N. W. T. Grieve, who carried out aortography on this case. We are grateful to Mr. N. L. Browse for his criticism of the manuscript.

Requests for reprints should be addressed to N. F. J.

\section{REFERENCES}

Barney, J. D., and Mintz, E. R. (1933). Journal of the American Medical Association, 100,

Bellman, S., and Odén, B. (1960). Acta Chirurgica Scandinavica, 120, 276.

Brest, A. N., Bower, R., and Heider, C. (1964). Journal of the American Medical Association, 187, 540

Duncan, D. A., and Dexter, R. N. (1962). New England fournal of Medicine, 266, 971 . Erskine, J. M., and Blaisdell, F. W. (1965). Archives of Surgery, 90, 247.
Goldsmith, E. I., Fuller, F. W., Lambrew, C. T., and Marshall, V. F. (1968). Fournal of Urology, 99, 366

Hoxie, H. J., and Coggin, C. B. (1940). Archives of Internal Medicine, 65, H. J.,

Loomis, R. C., Ocker, J. M., and Hodges, C. V. (1966). fournal of Urology, 96, 131 .

Morris, G. C., jun., Heider, C. F., and Moyer, J. H. (1955). Surgical Forum, 6, 623.

Perkins, R. P., Jacobson, D. S., Feider, F. P., Lipchik, E. O., and Fine, P. H. (1967). New England fournal of Medicine, 276, 1194.

Peterson, N. E., and McDonald, D. F. (1968). Fournal of Urology, 100, 140 .

Regan, F. C., and Crabtree, E. G. (1948). Journal of Urology, 59, 981. Smithwick, R. H., Newton, R. C., Crocker, D. H., and Harrison, J. H. (1964). American fournal of Surgery, 107, 104.

\title{
Effect of Drugs on Urate Binding to Plasma Proteins
}

\author{
RODNEY BLUESTONE,* M.B., M.R.C.P. ; IAN KIPPEN,† B.A. ; JAMES R. KLINENBERG,‡ M.D.
}

Summary : The effect of various drugs on urate binding $S$ to plasma proteins was investigated in normal subjects. Whereas allopurinol, aspirin, phenylbutazone, probenecid, and sulphinpyrazone all significantly reduced plasma urate concentrations, only aspirin, phenylbutazone, and probenecid significantly impaired urate binding. Colchicine and indomethacin in the doses administered had no significant effect on plasma urate concentrations or binding. In the case of aspirin, urate binding was reduced to $25 \%$ of normal, and this effect was quickly abolished after cessation of therapy. Phenylbutazone reduced urate binding to $56 \%$ and probenecid to $46 \%$ of normal ; this impairment was still detected four days after cessation of therapy. Drugs may impair urate binding by competition for plasma protein binding sites, with displacement of bound urate. Impairment of urate binding in vivo by administration of certain drugs may be relevant to the precipitation of acute gouty arthritis, to the formation of gouty tophi, and to the augmentation of uricosuria. Furthermore, the role of drugs must be seriously considered during all studies on urate binding in patients with gout.

* Postdoctoral Fellow.

t Supervising Research Technician.

F Assistant Professor of Medicine.

Fssistant Professor of Medicine. Los Angeles, California 90024

\section{Introduction}

The ability of human plasma proteins to bind uric acid has been demonstrated by means of several techniques (Shinaberger et al., 1964 ; Alvsaker, 1966 ; Sheikh and Møller, 1968). Although the significance of these observations has not been established they may be pertinent to the mechanisms of both the deposition of urate in tissue and the glomerular clearance of urate.

It has been postulated that urate binding to plasma proteins serves a protective role in the prevention of acute gout by increasing the solubility of urate in hyperuricaemic plasma (Alvsaker, 1966). Impaired binding would then facilitate increased urate deposition, with the consequent development of gouty arthritis and tophus formation (Seegmiller and Howell, 1962). Alvsaker (1966) has postulated the deficiency of a specific urate-binding globulin in some patients having primary gout. During experiments designed to characterize the urate-binding properties of human plasma, however, it was noted that salicylate significantly impaired urate binding (Klinenberg, 1968). Since a variety of drugs are used in the treatment of gout, it becomes necessary to test the effects of the drugs themselves on urate binding before postulating any basic defect of binding in this disease.

Furthermore, it has been assumed that uric acid is completely cleared at the renal glomerulus (Yü and Gutman, 1953); but if a proportion of plasma urate is protein-bound then renal clearance might not be complete. A possible mode of action 
of some uricosuric drugs would then be to increase the amount of free urate available for glomerular clearance.

We therefore studied the effect on urate binding to plasma in normal subjects of those drugs commonly administered to patients with gout.

\section{Materials and Methods}

Subjects and Drugs.- Healthy adult volunteers of both sexes were studied. They took no other medication for two weeks prior to and for the duration of the investigation. Allopurinol $400 \mathrm{mg}$./day, phenylbutazone $400 \mathrm{mg}$./day, probenecid $3 \mathrm{~g}$./day or sulphinpyrazone $400 \mathrm{mg}$./day were administered to six subjects each. Four subjects each were given colchicine $1.8 \mathrm{mg}$./day or indomethacin $150 \mathrm{mg}$./day. All drugs were administered orally in divided doses for seven days (days 1 to 7 , inclusive). Three subjects were intolerant of probenecid $3 \mathrm{~g}$./ day, so their dose was reduced to $1.5 \mathrm{~g}$./day from days 3 to 7 , inclusive.

Collection of Samples.-Thirty $\mathrm{ml}$. of blood was drawn by venepuncture into heparinized tubes from all subjects before treatment (day 0), and further samples were obtained on days 3 and 8 . Post-therapy samples were obtained on days 10 and 12 and, in some instances, on day 19. Blood samples were centrifuged, and the plasma was separated, divided into 3-ml. aliquots, and frozen until assayed (no longer than 14 days).

\section{Assays}

Aliquots from each sample were assayed for total plasma protein, albumin, and uric acid concentrations and urate binding capacity. Total plasma protein concentrations were determined by the modified biuret technique of Gornall et al. (1949). Albumin was assayed by cellulose acetate electrophoresis, using a Beckman microzone electrophoresis system. Plasma urate was determined by the enzymatic spectrophotometric method of Liddle et al. (1959).

Plasma-urate-binding capacity was assayed by a method of equilibrium dialysis recently reported (Klinenberg and Kippen, 1969). Three-ml. plasma aliquots were dialysed for 16 hours at $4^{\circ} \mathrm{C}$. against large volumes of $0.01 \mathrm{M}$ phosphate buffer containing $15 \mathrm{mg}$. uric acid per $100 \mathrm{ml}$. buffer. The plasma samples from one subject given allopurinol and from another given probenecid were also dialysed against buffers containing 5 and $10 \mathrm{mg}$. uric acid per $100 \mathrm{ml}$. buffer. After equilibration the amount of uric acid within the dialysis bag in excess of that in the buffer was considered to be bound. The amount of uric acid bound was expressed as $\mu \mathrm{g}$. $/ \mathrm{ml}$. plasma.

In order to compare urate binding capacity of a number of samples by this technique, it is necessary to select one or more free urate concentrations as points of reference. Fifteen $\mathrm{mg}$. per cent. urate was selected because there is a linear relationship between urate binding to plasma and free urate concentration up to $20 \mathrm{mg}$. urate per $100 \mathrm{ml}$. (Klinenberg and Kippen, 1969), and because the ability to detect differences between samples is greater at higher free urate concentrations.

\section{DEAE-Sephadex Chromatography}

Ion exchange chromatography was performed on plasma aliquots obtained from one subject on day 0 and on day 8 after probenecid or phenylbutazone therapy. DEAE-Sephadex (A-50) columns were prepared according to the manufacturer's recommendations and equilibrated with $0.05 \mathrm{M}$ sodium phosphate buffer, $p H$ 7.35. Samples were eluted with $0.01 \mathrm{M}$ sodium phosphate buffer, $\mathrm{pH} 7 \cdot 35$, containing $0 \cdot 2 \mathrm{M}$ sodium chloride. This procedure produced three distinct peaks, the third of which was shown to be predominantly albumin and accounted for most of the urate-binding capacity of normal plasma. These albumin peaks were dialysed exhaustively against $0.01 \mathrm{H}$ phosphate buffer and lyophilized. The uratebinding capacities of the redissolved albumin fractions were then measured by equilibrium dialysis.

\section{Results}

Plasma Proteins.-No significant alterations in total plasma protein or albumin concentrations were detected in any subject throughout the period of study.

Plasma Urate.-The effect of the drugs on plasma urate concentrations is shown in Table I. Allopurinol, aspirin, phenylbutazone, probenecid, and sulphinpyrazone significantly reduced the plasma urate concentrations. Urate concentrations returned to pre-drug values by day 12 following the administration of all the drugs except for phenylbutazone (Fig. 1). No significant depression of plasma urate was observed after the administration of colchicine or indomethacin.

\begin{tabular}{|c|c|c|c|c|c|}
\hline \multirow{2}{*}{ Drug } & \multirow{2}{*}{$\begin{array}{l}\text { No. of } \\
\text { Sub- } \\
\text { jects }\end{array}$} & \multicolumn{3}{|c|}{$\begin{array}{l}\text { Mean Plasma Urate mg. per } 100 \mathrm{ml} \\
( \pm \text { Standard Error of Mean })\end{array}$} & \multirow{2}{*}{$\begin{array}{c}\text { P for } \\
\text { Difference } \\
\text { between } \\
\text { Days } 0 \text { and } 8\end{array}$} \\
\hline & & Day 0 & Day 8 & Day 12 & \\
\hline $\begin{array}{ll}\text { Allopurinol } & \ldots \\
\text { Aspirin ... } & \ldots \\
\text { Colchicine } & \ldots \\
\text { Indomethacin } & \ldots \\
\text { Phenylbutazone } \\
\text { Probenecid } \\
\text { Sulphinpyrazone }\end{array}$ & $\begin{array}{l}6 \\
6 \\
4 \\
4 \\
6 \\
6 \\
6 \\
6\end{array}$ & $\begin{array}{l}4 \cdot 8( \pm 0 \cdot 6) \\
5 \cdot 1( \pm 0 \cdot 6) \\
4 \cdot 8( \pm 0 \cdot 4) \\
6 \cdot 1( \pm 0 \cdot 5) \\
5 \cdot 1( \pm 0 \cdot 6) \\
4 \cdot 2( \pm 0 \cdot 4) \\
5 \cdot 6( \pm 0.6)\end{array}$ & $\begin{array}{l}2 \cdot 3( \pm 0 \cdot 4) \\
2 \cdot 2( \pm 0 \cdot 3) \\
4 \cdot 5( \pm 0 \cdot 4) \\
5 \cdot 9( \pm 0 \cdot 5) \\
3 \cdot 0( \pm 0 \cdot 4) \\
2 \cdot 1( \pm 0 \cdot 1) \\
2 \cdot 2( \pm 0 \cdot 4)\end{array}$ & $\begin{array}{l}4 \cdot 2( \pm 0 \cdot 4) \\
4 \cdot 7( \pm 0 \cdot 3) \\
4 \cdot 6( \pm 0 \cdot 4) \\
6 \cdot 2( \pm 0 \cdot 5) \\
3 \cdot 9( \pm 0 \cdot 4) \\
5 \cdot 0( \pm 0 \cdot 5) \\
4 \cdot 8( \pm 0 \cdot 3)\end{array}$ & $\begin{array}{l}<0.01^{\circ} \\
<0.01^{\circ} \\
>0.5 \\
>0.5 \\
<0.02^{\circ} \\
<0.001^{\circ} \\
<0.001^{\circ}\end{array}$ \\
\hline
\end{tabular}

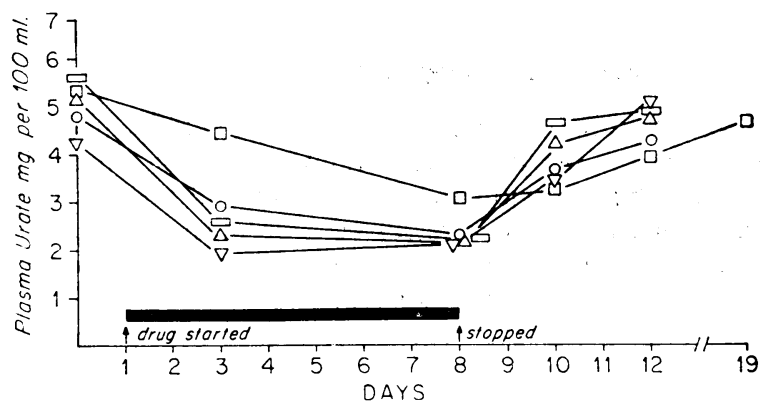

FIG. 1.-Effect of drugs on plasma urate levels: allopurinol

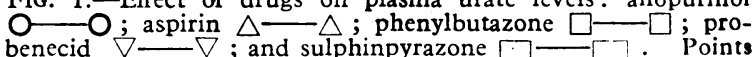
are mean values for six subjects.

\section{Plasma Urate Binding}

The effect of the drugs on plasma urate binding is shown in Table II. Aspirin impaired binding from 24.8 $( \pm 1.7)$ to $6.8( \pm 1 \cdot 7) \mu \mathrm{g} . / \mathrm{ml}$. plasma by day 8 following administration $(\mathrm{P}<0.001)$. Probenecid impaired binding from 33.7 $( \pm 2.3)$ to $15.5( \pm 2.8) \mu \mathrm{g} . / \mathrm{ml}$. $(\mathrm{P}<0.001)$, and phenylbutazone from $24.3( \pm 1.2)$ to $13.8( \pm 0.7) \mu \mathrm{g} . / \mathrm{ml}$. $(P<0.001)$. The impaired binding associated with all three drugs was apparent by day 3 following their administration (Fig. 2). In the case of phenylbutazone and probenecid the impaired urate binding was still apparent by day 12 ; that associated with aspirin was no longer apparent by day 10 . No significant impairment of urate binding was observed after the administration of allopurinol, colchicine, indomethacin, or sulphinpyrazone.

The dose of probenecid in excess of $1.5 \mathrm{~g}$. daily was found to have little additional effect on urate binding; the impairment of urate binding was comparable in the three subjects taking probenecid 1.5 daily to those taking the full $3 \mathrm{~g}$. dose. Administration of allopurinol and probenecid did not alter the linear 
relationship between the plasma urate bound and the free urate concentration up to a free urate concentration of $15 \mathrm{mg} . / 100$ ml. buffer.

TABLE II.-Effect of Drugs on Urate Binding to Plasma Proteins

\begin{tabular}{|c|c|c|c|c|c|}
\hline \multirow[t]{2}{*}{ Drug } & \multirow[t]{2}{*}{$\begin{array}{l}\text { No. of } \\
\text { Sub- } \\
\text { jects }\end{array}$} & \multicolumn{3}{|c|}{$\begin{array}{l}\text { Mean Urate Binding Capacity } \\
\text { ( } \mu \text { g. Urate Bound per ml. Plasma } \\
\pm \text { Standard Error of Mean) }\end{array}$} & \multirow{2}{*}{$\begin{array}{c}P \text { for } \\
\text { difference } \\
\text { between } \\
\text { Days } \\
0 \text { and } 8\end{array}$} \\
\hline & & Day 0 & Day 8 & Day 12 & \\
\hline $\begin{array}{ll}\text { Allopurinol } & . \\
\text { Aspirin .. } & \ldots \\
\text { Colchicine } & \ldots \\
\text { Indomethacin } & . . \\
\text { Phenylbutazone } \\
\text { Probenecid . } \\
\text { Sulphinpyrazone }\end{array}$ & $\begin{array}{l}6 \\
6 \\
4 \\
4 \\
6 \\
6 \\
6\end{array}$ & $\begin{array}{l}29 \cdot 2( \pm 0 \cdot 9) \\
24 \cdot 8( \pm 1 \cdot 7) \\
32 \cdot 8( \pm 1 \cdot 8) \\
29 \cdot 3( \pm 0 \cdot 9) \\
24 \cdot 3( \pm 1 \cdot 2) \\
33 \cdot 7 \cdot( \pm 2 \cdot 3) \\
30 \cdot 3( \pm 2 \cdot 2)\end{array}$ & $\begin{array}{r}27 \cdot 5( \pm 0 \cdot 4) \\
6 \cdot 8( \pm 1 \cdot 7) \\
33 \cdot 0( \pm 2 \cdot 4) \\
25 \cdot 5( \pm 0 \cdot 9) \\
13 \cdot 8( \pm 0 \cdot 7) \\
15 \cdot 5( \pm 2 \cdot 8) \\
26 \cdot 0( \pm 1 \cdot 3)\end{array}$ & $\begin{array}{l}28 \cdot 7( \pm 1 \cdot 4) \\
30 \cdot 7( \pm 1 \cdot 4) \\
29 \cdot 5( \pm 2 \cdot 9) \\
28 \cdot 8( \pm 1 \cdot 0) \\
19 \cdot 0( \pm 1 \cdot 8) \\
21 \cdot 2( \pm 2 \cdot 0) \\
29 \cdot 3( \pm 1 \cdot 5)\end{array}$ & $\begin{array}{l}>0.1 \\
<0.001 * \\
>0.5 \\
>0.02 \\
<0.001 * \\
<0.001 * \\
>0.1\end{array}$ \\
\hline
\end{tabular}

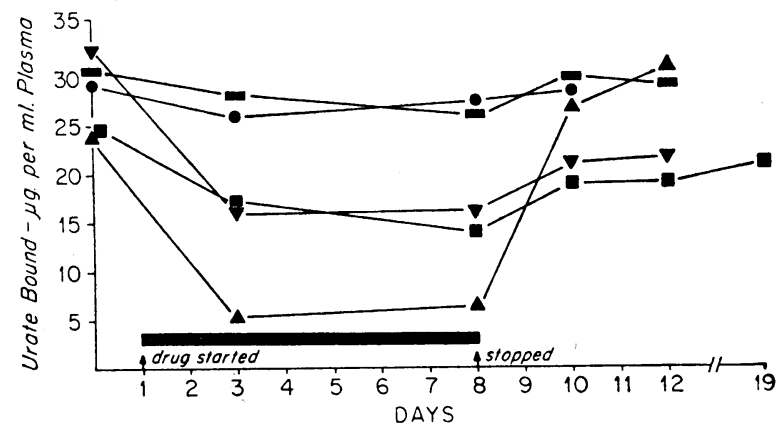

Fig. 2.-Effect of drugs on plasma urate binding capacity at a free urate concentration of $15 \mathrm{mg}$. per $100 \mathrm{ml}$.: allopurinol
benecid ; aspirin ; proare mean values for six subjects.

\section{DEAE-Sephadex Chromatography}

The plasma aliquot obtained from one subject before any therapy showed normal urate binding. Those obtained on day 8 following phenylbutazone or probenecid therapy showed impaired binding. The redissolved lyophilized albumin fractions extracted from all three samples, however, possessed equal, and normal, urate binding capacities.

\section{Discussion}

This study has shown that administration of aspirin, phenylbutazone, or probenecid to normal subjects results in impaired binding of urate to plasma proteins. This impairment was gross in the case of aspirin, with the urate binding reduced to $25 \%$ of normal ; but this effect quickly diminished after cessation of therapy. Probenecid reduced urate binding to $47 \%$ of normal, but this effect was more sustained, diminished binding still being detected four days after stopping the drug. Moreover, those subjects taking probenecid $1.5 \mathrm{~g}$./day on days 3 to 8 showed as much reduction of binding capacity as subjects taking the full 3-g. dose. Phenylbutazone resulted in a $56 \%$ reduction of urate binding, this effect likewise being still evident four days after cessation of the drug.

Although the clinical significance of these studies has not yet been established, urate binding under physiological conditions does occur (Shinaberger et al., 1964). It is thus possible that impairment of urate binding in vivo might result in more "free" uric acid being available for deposition within the tissues. Conversely, the binding of a significant proportion of plasma urate in hyperuricaemic subjects might play a protective part in the prevention of acute gout.

The three drugs which caused impaired urate binding in the doses administered are known uricosuric agents. Although it is postulated that uricosuric agents exert their main effect at the renal tubular level (Gutman and Yü, 1958), it is conceivable that their inhibition of urate binding could facilitate an increased glomerular urate clearance, with subsequent augmentation of the uricosuric effect. It has been thought that, normally, uric acid is completely cleared at the renal glomerulus (Y $\ddot{u}$ and Gutman, 1953). Bound urate, however, might not be freely filtered at the glomerulus, and clearance would then not be complete. Not all uricosuric drugs, however, impair urate binding. Thus the subjects taking sulphinpyrazone all demonstrated uricosuria but had normal urate binding.

If a uricosuric drug were to impair urate binding in a hyperuricaemic subject before adequate uricosuria occurred, then urate released from the protein might facilitate the production of gout. This might partially explain the well-recognized exacerbation of gouty arthritis which sometimes occurs during initiation of uricosuric therapy. It might also account for the relative ineffectiveness of uricosuric doses of aspirin in preventing acute gout.

The precise mechanism for drug inhibition of urate binding to plasma proteins has not yet been delineated. The fact that ion exchange chromatography restored normal urate binding capacities to the plasma albumin fractions suggests that a gross structural change of albumin molecules is unlikely. In addition, no quantitative changes in plasma protein or albumin levels during drug administration were detected. Aspirin has been shown to result in acetylation of albumin in vivo (Hawkins et al., 1969) but this effect cannot explain our findings, since urate binding returned to normal within two days of stopping the drug.

Competition for plasma-protein-binding sites between drug and urate molecules is a likely possibility. Similar mechanisms have been demonstrated for the displacement of other proteinbound substances by anti-inflammatory agents (Brodie, 1965), including salicylate anions (Odell et al., 1969), indomethacin, phenylbutazone (Aggeler et al., 1967), and sulphinpyrazone. Furthermore, salicylate, phenylbutazone, and probenecid seem to share a common binding site on the albumin molecule (Whitehouse, personal communication, 1969). Since the urate/ protein bond is a weak one, displacement of urate by a drug would be facilitated. The failure of indomethacin, a drug which is extensively protein-bound, to produce significant impairment of urate binding may be explained by the low plasma drug concentrations achieved with normal doses of indomethacin (Hucker et al., 1966). Likewise, the failure of sulphinpyrazone to impair urate binding significantly may reflect the fact that it may have a different binding site from the other drugs on the albumin molecule (Whitehouse, personal communication, 1969). Allopurinol is not protein-bound (Elion et al., 1966), and apparently does not affect urate binding. The binding of colchicine, and its metabolism, is not well understood, and in any event the small doses administered in this study would result in low plasma concentrations (Ertel et al., 1969).

It is apparent that when studying the plasma of gouty subjects for urate binding one must consider the effects of current or recent drug therapy. Previous reports have not taken these into account. Indeed, the occurrence of familial gout and impaired urate binding, ascribed to a hereditary deficiency of urate binding globulin, was recently described in a family with a long history of migraine (Alvsaker, 1968). The members of this family were taking large quantities of analgesics. The normal subjects whom we studied were given single drugs for only seven days, so we sre unable to assess the possible effects of long-term or combired drug therapy on urate binding. Nevertheless, the evidence suggests that the role of drugs must be carefuily considered when studying urate binding in gout. It is imperative, before undertaking such studies, that all therapy likely to impair binding should be stopped. 
We thank Mrs. Wakakuwa for her expert technical assistance and Dr. M. W. Whitehouse for helpful discussion. Dr. Rodney Bluestone is the recipient of an Arthritis and Rheumatism Council of Great Britain Travelling Fellowship and of a Wellcome Research Travel Grant. This study was supported by USPHS Grant No. GM 15759.

\section{REFERENCES}

Aggeler, P. M., O'Reilly, R. A., Leong, L., and Kowitz, P. E. (1967). New England fournal of Medicine, 276, 496

Alvsaker, J. O. (1966). Scandinavian fournal of Clinical and Laboratory Investigation, 18, 227.

Alvsaker, J. O. (1968). fournal of Clinical Investigation, 47, 1254. Brodie, B. B. (1965). Proceedings of the Royal Society of Medicine, 58,946

Elion, G. B., Kovensky, A., Hitchings, G. H., Metz, E., and Rundles, R. W. (1966) Biochemical Pharmacology, 15,863.

Ertel, N., Omokoku, B., and Wallace, S. L. (1969). Arthritis and Rheumatism, 12, 293.
Gornall, A. G., Bardawill, C. J., and David, M. M. (1949). Fournal of Biological Chemistry, 177, 751.

Gutman, A. B., and Yü, T. F. (1958). Bulletin of the New York Academy of Medicine, 34, 287.

Hawkins, D., Pinckard, R. N., Crawford, I. P., and Farr, R. S. (1969). fournal of Clinical Investigation, 48, 536.

Hucker, H. B., Zacchei, A. G., Cox, S. V., Brodie, D. A., and Cantwell N. H. R. (1966). fournal of Pharmacology and Experimental Therapeutics, 153,237.

Klinenberg, J. R. (1968). Arthritis and Rheumatism, 11, 828.

Klinenberg, J. R., and Kippen, I. (1969). In preparation.

Liddle, L., Seegmiller, J. E., and Laster, L. (1959). Fournal of Laboratory and Clinical Medicine, 54, 903.

Odell, G. B., Cohen, S. N., and Kelly, P. C. (1969). Fournal of Pediatrics, 74, 214.

Seegmiller, J. E., and Howell, R. R. (1962). Arthritis and Rheumatism,

5, 616.

158, 456.
Shinaberger, J. H., Pabico, R. C., Shear, L., Knochel, J. P., and Barry, K. G. (1964). Clinical Research, 12, 463.

Yü, T. F., and Gutman, A. B. (1953). Proceedings of the Society of Experimental Biology and Medicine, 84, 21.

\title{
Changing Faecal Population of Escherichia coli in Hospital Medical Patients
}

\author{
E. MARY COOKE,* B.SC., M.D., M.C.PATH.; SUSAN EWINS, $\dagger$ A.I.M.L.T. \\ R. A. SHOOTER, $\ddagger$ M.D., F.R.C.P., F.C.PATH.
}

British Medical fournal, 1969, 4, 593-595

\begin{abstract}
Summary : Specimens of faeces were obtained at weekly $\checkmark$ intervals for one year from patients in a female medical ward and Escherichia coli present were typed. The faecal $E$. coli population of the patients was constantly changing. No serotypes of $\mathbf{E}$. coli were dominant, but on 31 occasions during the year small clusters of patients carried the same type.
\end{abstract}

\section{Introduction}

Previous workers have found that the serotypes of Escherichia coli present in the bowel of an individual may be relatively constant over long periods of time (Sears, Brownlee, and Uchiyama, 1950) and that it may be difficult to change the faecal $E$. coli population (Sears, Janes, Saloum, Brownlee, and Lamoreaux, 1956). Kennedy, Plorde, and Petersdorf (1965) and Winterbauer, Turck, and Petersdorf (1967), however, have shown that certain serotypes of $E$. coli are more commonly found in the faeces of hospital inpatients than in the general population, suggesting that under these conditions the $E$. coli bowel flora may change.

The investigations reported here were carried out to study in some detail the faecal carriage of $E$. coli by patients in one hospital ward.

\section{Material and Methods}

The work was done during one year in a female open medical ward which had 24 beds and one further bed in a single side-room. The patients were those seen in a general medical ward, and included particularly diabetic patients and patients with diseases of the bowel.

Specimens of Faeces.-We tried to obtain specimens from each patient as soon as possible after admission and thereafter

* Senior Lecturer in Bacteriology.

+ Technician

¥ Professor of Bacteriology.

St. Bartholomew's Hospital, London E.C.1. at weekly intervals. In addition each stool passed by 32 patients during one week was examined.

Specimens of Urine.-These were midstream specimens sent in routinely because urinary tract infection was suspected. The presence of an excess of white cells in the urine and of a bacilluria (of $10^{5}$ or more) were the criteria taken for considering the patient to be infected.

\section{Method of Faeces Examination}

The faeces were inoculated on to a MacConkey plate by means of a cotton-wool swab. After overnight incubation the plates were examined and five colonies of each colonial type of coliform present were subcultured on to blood agar. The identity of these coliforms as Escherichia was confirmed by determination of the following reactions: fermentation of lactose and glucose, production of indole, and failure to produce urease or to utilize citrate. The $E$. coli were inoculated into $10 \mathrm{ml}$. of broth which was incubated overnight, steamed for 30 minutes, and then used for serotyping the organism.

Antisera to $O$ groups $1-25,39$, and 75 were prepared by the method of Roschka (1950). The cross-reactions of the antisera with the type strains of $148 \mathrm{E}$. coli $\mathrm{O}$ groups were determined, and absorbed sera were prepared as described by Bettelheim and Taylor (1969).

The antisera were grouped into five pools; $0.3 \mathrm{ml}$. of bacterial suspension was added to $0.3 \mathrm{ml}$. of antiserum in a Dreyer's tube, incubated at $50^{\circ} \mathrm{C}$. for 18 hours, and then read. When a positive result was obtained the organism was tested against the monovalent antisera of the group. The identity of the organisms was confirmed by titration of the antisera, and, when necessary, by use of absorbed antisera.

\section{Results}

Examination of 1,136 specimens of faeces from 303 patients was made. From 234 of the patients typable strains of $E$. coli 